\title{
Epstein-Barr Virus-Associated Primary Central Nervous System Lymphoma in the Japanese Population
}

\author{
Ryuhei KITAI, Ken MATSUDA, Erika ADACHI, Yasushi SAITO, \\ Tsuyoshi NAKAJIMA, Hiroaki TAKEUCHI, Kazufumi SATO, \\ Yoshiaki IMAMURA*, and Toshihiko KUBOTA \\ Department of Neurosurgery, Faculty of Medical Sciences, University of Fukui, Fukui; \\ ${ }^{*}$ Division of Surgical Pathology, University of Fukui Hospital, Fukui
}

\begin{abstract}
The incidence of Epstein-Barr virus (EBV)-associated primary central nervous system (CNS) lymphoma in Japan was assessed using in situ hybridization of EBV-encoded small ribonucleic acid-1 (EBER-1) to identify the presence of EBV in 22 cases of formalin-fixed and paraffin-embedded primary CNS lymphoma. All cases were B-cell lymphoma. EBER-1 expression was observed in the nuclei of 3 of 22 primary CNS lymphoma cases (13.6\%). The incidence of EBV-positive lymphoma in Japanese cases is higher than previously reported from Western countries. Patients with EBV-positive primary CNS lymphoma showed shorter survival than those with negative tumors (median 4 months vs. 26 months). EBER-1 in situ hybridization for the detection of EBV infection is rapid and reliable. Infrequent association suggests a different pathogenetic mechanism in the evolution of these tumors. Geographical differences in the incidence of EBV-associated primary CNS lymphoma may reflect epidemiological factors.
\end{abstract}

Key words: Epstein-Barr virus, Japan, immunocompromised patient, primary central nervous system lymphoma

\section{Introduction}

Epstein-Barr virus (EBV) is a gamma herpes virus found in $>90 \%$ of the general population. ${ }^{32)}$ Serological testing for EBV revealed that more than $90 \%$ of the infected people in Japan were infected during childhood or adolescence. ${ }^{15)}$ Infection usually occurs through contact with oral secretions. Primary infection often results in infectious mononucleosis. ${ }^{12,32)}$ EBV infects various types of cells, such as $T$ and B lymphocytes, squamous epithelial cells of the oropharynx and nasopharynx, and glandular epithelium (e.g. of the thyroid, stomach, or salivary gland). ${ }^{5,10,28,32)}$ The virus persists for life in the human host by evading the immune system via latent infection of B lymphocytes, which are the major cellular reservoir, ${ }^{18)}$ with healthy virus carriers harboring 1-50 EBV genomes per one million B cells. ${ }^{10)}$ Infected cells show dual phases of latent viral persistence and lytic viral replication. ${ }^{8,12,15,29)}$

EBV is associated with several malignant diseases, including Burkitt's lymphoma, ${ }^{33)}$ systemic B-cell lymphomas in acquired immunodeficiency syn-

Received January 8, 2009; Accepted May 26, 2009 drome (AIDS) patients, ${ }^{25)}$ non-Hodgkin's lymphomas, ${ }^{9)}$ EBV-associated carcinomas in the salivary and parotid glands, ${ }^{10,31)}$ and gastric cancers. ${ }^{28)}$ Associated malignancies are thought to usually be the result of virus reactivation. ${ }^{12)}$ Reports from industrialized countries over the last two decades have shown a more than 10 -fold increase in the incidence of primary central nervous system (CNS) lymphoma, partly associated with the AIDS epidemic, but also in immunocompetent individuals. ${ }^{7,8)}$ The incidence of primary CNS lymphoma is 3600 -fold higher in individuals with AIDS than in the general population ${ }^{8)}$ and patients with this type of lymphoma typically have a CD4 lymphocyte count below 50 cells $/ \mathrm{mm}^{3}{ }^{30}$ probably due to a deficiency in cytotoxic T-cells that permits the outgrowth of EBVtransformed B-cells. ${ }^{1,8,20,32)}$ Surprisingly, most cases of primary CNS lymphoma in AIDS patients were reported to be EBV related,,35) although primary CNS lymphoma occurring in immunocompetent individuals was infrequently associated with the virus in previous reports from Europe and North Ameri$\mathrm{ca}^{2,4,6,11,13,24,32)}$ Systemic diffuse large B-cell lympho$\mathrm{ma}$ is also infrequently associated with EBV. ${ }^{27,29)}$ Examination of the EBV association with systemic 
B-cell lymphoma in 72 Japanese patients found positive signals in $17 \%$ of cases. ${ }^{16)}$ EBV-deoxyribonucleic acid (DNA) is detected in the tumor tissue of virtually all AIDS-related CNS lymphomas, ${ }^{1,4,12,22,32)}$ but reactivation of $\mathrm{EBV}$ is very rare in patients without human immunodeficiency virus (HIV) infection. . $^{2,4,6,11,12,25,32)}$

The present study investigated the incidence of EBV-associated primary CNS lymphoma in the Japanese population, for comparison with that in Western countries to evaluate the significance of epidemiopathologic and clinical characteristics.

\section{Patients and Methods}

Twenty-two patients with primary CNS lymphoma, 10 males and 12 females aged 50 to 82 years old (median 65.0 years old), were referred after biopsy/surgery at Fukui University Hospital (Table 1). According to the World Health Organization classification of brain tumors, primary CNS lymphoma is defined as malignant lymphoma arising in the CNS in the absence of obvious lymphoma outside the nervous system at the time of diagnosis. ${ }^{19)}$

The initial presenting symptoms and signs involved the CNS and no peripheral lymphadenopathy, organomegaly, or evidence of bone marrow involvement was found at presentation. No histories or clinical findings suggested immunocompromised state, except in one patient (Case 22), who was HIV negative. The HIV status was unknown but considered negative based on the clinical criteria, age, and the year of onset in the other patients. After definite diagnosis, the patients underwent chemotherapy and/or radiotherapy. Unfortunately, the adjuvant chemoradiotherapy was different in various patients. Recently, intensive chemotherapy with the high-dose methotrexate regimen was adopted prior to the radiotherapy (Table 1). The median survival time was calculated by the Kaplan-Meier method.

Surgical specimens were fixed in formalin and

Table 1 Clinicopathological findings and in-situ hybridization of Epstein-Barr virus (EBV)

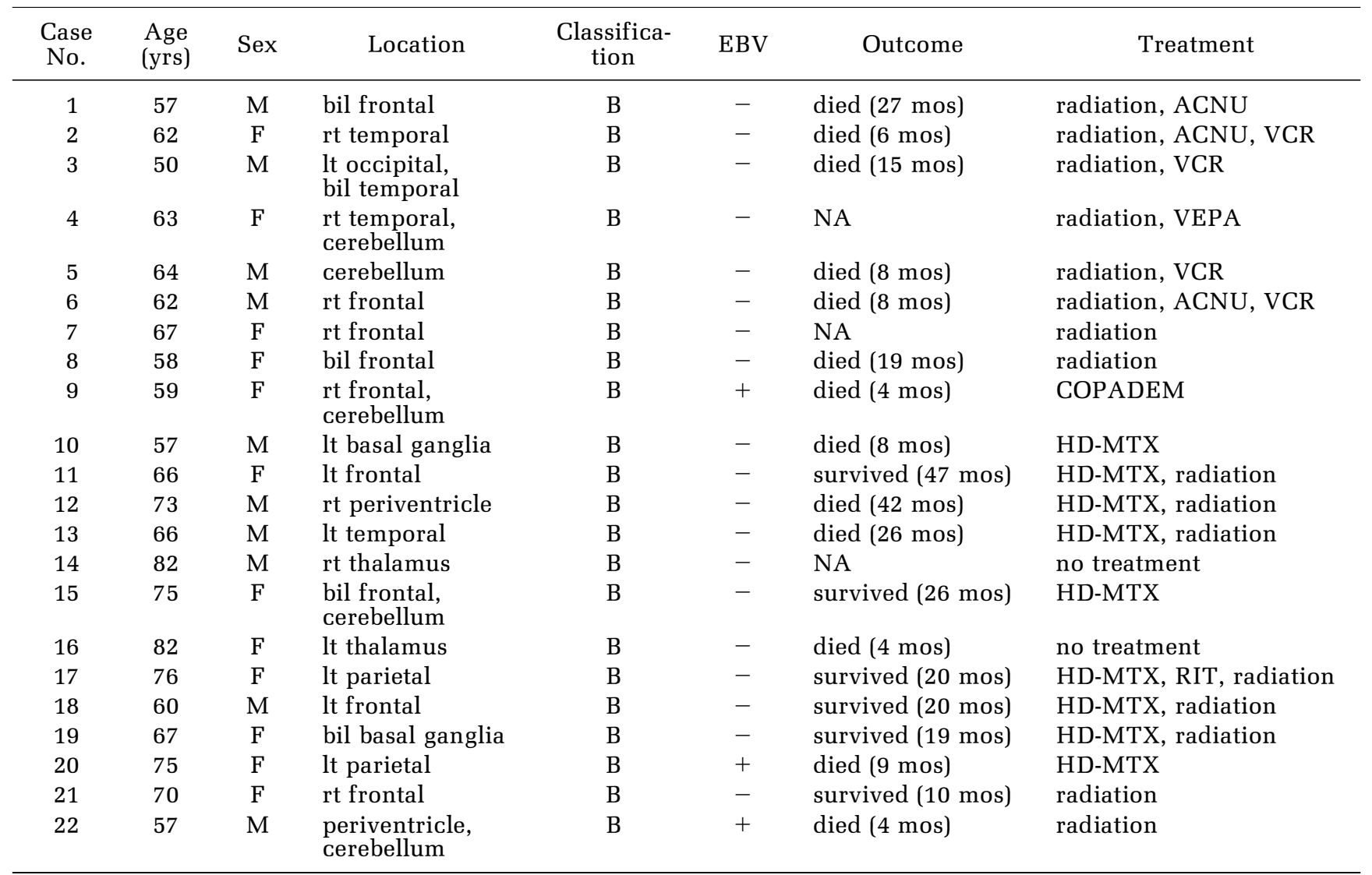

ACNU: nimustine hydrochloride; COPADEM: combined chemotherapy with vincristine, methotrexate, hydrocortisone, folinic acid, adriamycin, cyclophosphamide, and methylprednisolone ${ }^{3)}$; HD-MTX: high-dose methotrexate; NA: not assessed; RIT: Rituximab; VCR: vincristine; VEPA: combined chemotherapy with vinblastine, etoposide, prednisone, and doxorubicin. ${ }^{23)}$ 
routinely processed for paraffin embedding. Histological sections were stained with hematoxylin and eosin. Immunohistochemical staining used primary antibodies against CD45 (leukocyte common antigen, DAKO M0701 1:100; Dako Denmark A/S, Glostrup, Denmark), CD20 (B cell marker, DAKO M755 1:100; Dako Denmark A/S), and CD45RO (T cell marker, DAKO M0742, 1:100; Dako Denmark A/S). The negative control was a parallel section treated as above with the omission of primary antibody. The staining procedure was achieved by the Envision plus technique (Dako Japan, Tokyo). Detailed histological diagnoses were reviewed by R.K., T.K., and Y.I.

EBV was identified by the expression of EBV-encoded small ribonucleic acid-1 (EBER-1), the most abundant viral product in latently infected cells. ${ }^{5,12)}$ EBER-1 expression was detected using a complementary fluorescein isothiocyanate (FITC)-labeled oligomer of a commercially available probe (Boehringer, Mannheim, Germany). Briefly, $4 \mu \mathrm{m}$ paraffin sections were cut from the main tumor, deparaffinized, rehydrated, and hybridized overnight at $42^{\circ} \mathrm{C}$ with probes. After repeated stringent washing, probe detection was conducted with alkaline phosphatase-conjugated anti-FITC monoclonal antibody and alkaline phosphatase substrates (5bromo-4-chloro-3-indoyl-phosphate/nitroblue tetrazolium). EBV-associated gastric cancer was used as a positive control. Repeated studies were performed.

Detection of a strong positive signal in the large majority of identifiable viable tumor cells was considered to indicate EBV association. Specimens containing a few positive cells around the vasculature were excluded, because non-neoplastic EBER-1positive lymphocytes are well known to be scattered within the tumor tissue or adjacent nodal tissue in systemic lymphoma. ${ }^{12)}$

\section{Results}

The tumors were supratentorial in 21 cases, most commonly in the frontal and parietal regions. Multiple tumors were found in 8 cases. The brainstem and cerebellum were involved in 5 cases. The right and left hemispheres were involved with equal frequency (Table 1).

The diagnosis of malignant lymphoma was agreed by the authors. In general, the specimen showed compact cellular aggregates with angiocentric infiltrating pattern. Mitotic features and apoptosis of lymphoma cells were also prominent. Immunohistochemically, positive reactions of lymphoma cells for CD20 (Fig. 1A) and negative reactions for CD45RO were observed in all patients, indicating B

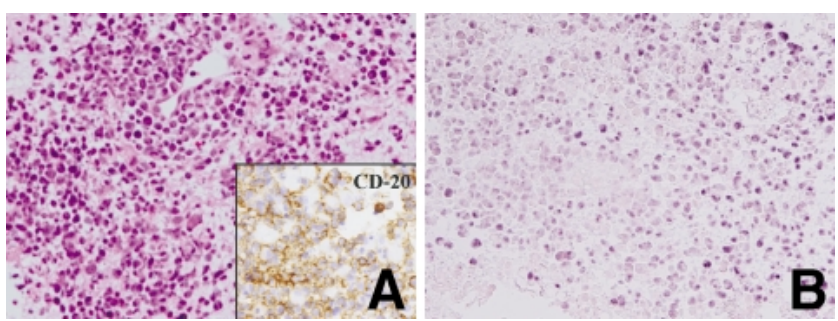

Fig. 1 A: Case 22. Photomicrograph showing dense atypical cells with angiocentric pattern. Hematoxylin and eosin stain, original magnification $\times 100$. Inset: CD-20 immunostain, $\times 200$. B: Case 22. Photomicrograph showing strong expression of Epstein-Barr virusencoded small ribonucleic acid-1 in the nuclei of lymphoma cells by in situ hybridization. Blue nuclear stain with neutral red counterstain, original magnification $\times$ 100.

cell origin. Scattered mature $\mathrm{T}$ cells were evident. All diagnoses were B cell lymphoma. Positive EBV signal was observed by in situ hybridization in 3 of $22(13.6 \%)$ cases (Table 1$)$. The signals were specifically localized in the nuclei of tumor cells (Fig. 1B), but were absent in the surrounding normal brain tissue. No morphologic differences could be discerned between EBV-positive and EBV-negative tumors.

Logistic analysis did not reveal any significant differences between age correlation and EBV infection. The survival times of patients with EBV-associated primary CNS lymphoma were shorter than those with negative association. The median survival time of EBV-positive patients was 4 months and that of EBV-negative patients was 26 months (Kaplan-Meier method, data not shown). However, the number of patients was small and adjuvant therapy varied among cases.

\section{Discussion}

The present study found the incidence of EBV-associated primary CNS lymphoma in Japanese patients was $13.6 \%$, higher than in previous studies worldwide. ${ }^{2,4,6,11,13,21,26,32)}$ Examination of 41 primary CNS lymphoma cases in Denmark showed that only two tumors (4.9\%) were EBER-1 positive. ${ }^{21)}$ EBVpositive primary CNS lymphoma accounted for only three $(7.0 \%)$ of 43 immunocompetent patients in England. ${ }^{11)}$ There were two reports from North America. Only one of 27 primary CNS lymphoma immunocompetent patients $(3.7 \%)$ was EBER-1 positive, ${ }^{6)}$ and none of four CNS lymphomas in immunocompetent patients showed any reactivity with the EBV sequence, BamH1V in North America. ${ }^{2)} \mathrm{Re}-$ cent reviews have suggested that about $5 \%$ of prima- 
ry CNS lymphomas in non-immunocompromised patients are EBV associated. ${ }^{12,32)}$ Examination of 3 Japanese cases for EBV infection found no EBVpositive primary CNS lymphoma using polymerase chain reaction (PCR) for the EBV genome. ${ }^{17}$

Laboratory detection of EBV is accomplished in several ways. Paraffin-section DNA in situ hybridization using radiolabeled probes is a difficult and time-consuming technique. The demonstration of EBV-DNA by Southern blotting generally requires frozen tumor tissue. Detection of EBV-associated antigens, such as latent membrane protein-1 by immunohistochemistry, is not consistently positive due to the variable expression profiles. ${ }^{12,13)}$ Developing new detection technology and commercially available EBER-1 hybridization probes will provide faster and more reliable results. EBER-1 is transcribed in abundance (up to $10^{7}$ copies per cell) in all forms of EBV latency. ${ }^{2,12,13,21)}$ Thus, single-figure EBV genome copies can be detected in routine tissue sections using nonisotopic in situ hybridization, which is the gold standard for investigating the disease association of EBV. ${ }^{12)}$ EBER-1 in situ hybridization is reported to be similar to Southern blot analysis of frozen tissue for EBV-DNA. ${ }^{13)}$ In addition, this method provides useful topographic information concerning the nature of the infected cells in EBVpositive cells, but is not available for destructive techniques such as standard PCR. A PCR-based detecting system cannot exclude the possibility that EBV-positive cases may represent an amplification of EBV-DNA in reactive lymphocytes which are often encountered in tumor tissue. ${ }^{12,13)}$

This study and previous reports ${ }^{11-13,21)}$ uphold a link between EBV and primary CNS lymphoma, but the incidence is low, suggesting different oncogenic mechanisms. Patients with EBV-positive primary CNS lymphoma showed shorter survival in our series. In general, primary CNS lymphoma in immunocompromised patients shows very rapid neurological deterioration and a dismal prognosis. ${ }^{11)}$ Although there is no accepted consensus regarding prognosis and EBV association, EBV infection and/or reactivation might be a terminal event during the primary CNS lymphoma clinical course due to local immunosuppression. However, this study was quite small, so no definitive conclusion can be made.

Antiviral therapy has not demonstrated clinical efficacy in the treatment of EBV-related CNS disorders. ${ }^{32)}$ Treatment was successful in a 24-year-old female patient with EBV-associated lymphoma and CNS involvement using intravenous rituximab (375 $\mathrm{mg} / \mathrm{m}^{2}$ once weekly for 4 weeks) and cidofovir (5 $\mathrm{mg} / \mathrm{kg}$ once weekly for 3 weeks). ${ }^{14)}$ Complete remission with regression of the peripheral lymphomas and disappearance of neurological symptoms was seen. Additionally, EBV-DNA, assessed using PCR, became negative in both plasma and cerebrospinal fluid.

The present study revealed that the incidence of EBV-associated primary CNS lymphoma in Japan was higher than previously reported, which might reflect epidemiologic or ethnic factors. The newly developed detection kit was important in these results. The infrequent association of EBV suggests a partial role in oncogenesis. Further studies on a larger number of patients are essential to resolve this issue of the oncogenic association of the virus.

\section{Acknowledgment}

This study was supported by a grant from the Research and Education Program for Life Science, University of Fukui, 2007.

\section{References}

1) Ambinder RF: Epstein-Barr virus associated lymphoproliferations in the AIDS setting. Eur J Cancer 37: 1209-1216, 2001

2) Bashir RM, Harris NL, Hochberg FH, Singer RM: Detection of Epstein-Barr virus in CNS lymphomas by in-situ hybridization. Neurology 39: 813-817, 1989

3) Blay JY, Bouhour D, Carrie C, Bouffet E, BrunatMentigny M, Philip T, Biron P: The C5R protocol: a regimen of high-dose chemotherapy and radiotherapy in primary cerebral non-Hodgkin's lymphoma of patients with no known cause of immunosuppression. Blood 86: 2922-2929, 1995

4) Camilleri-Broët S, Martin A, Moreau A, Angonin R, Hénin D, Gontier MF, Rousselet MC, Caulet-Maugendre S, Cuillière $\mathrm{P}$, Lefrancq T, Mokhtari K, Morcos M, Broët P, Kujas M, Hauw JJ, Desablens B, Raphaël M: Primary central nervous system lymphomas in 72 immunocompetent patients: pathologic findings and clinical correlations. Groupe Ouest Est d'etude des Leucenies et Autres Maladies du Sang (GOELAMS). Am J Clin Pathol 110: 607-612, 1998

5) Chang KL, Chen YY, Shibata D, Weiss LM: Description of an in situ hybridization methodology for detection of Epstein-Barr virus RNA in paraffin-embedded tissues, with a survey of normal and neoplastic tissues. Diagn Mol Pathol 1: 246-255, 1992

6) Chang KL, Flaris N, Hickey WF, Johnson RM, Meyer JS, Weiss LM: Brain lymphomas of immunocompetent and immunocompromised patients: study of the association with Epstein-Barr virus. Mod Pathol 6: 427-432, 1993

7) Corn BW, Marcus SM, Topham A, Hauck W, Curran WJ Jr: Will primary central nervous system lymphoma be the most frequent brain tumour diagnosed in the year 2000? Cancer 79: 2409-2413, 1997

8) Coté TR, Manns A, Hardy CR, Yellin FJ, Hartge P: Epidemiology of brain lymphoma among people with or without acquired immunodeficiency syndrome. AIDS/Cancer Study Group. J Natl Cancer Inst 88: 
675-679, 1996

9) Elenitoba-Johnson KS, Jaffe ES: Lymphoproliferative disorders associated with congenital immunodeficiencies. Semin Diagn Pathol 14: 35-47, 1997

10) Gallo O, Santucci M, Calzolari A, Storchi OF: Epstein-Barr virus (EBV) infection and undifferentiated carcinoma of the parotid gland in Caucasian patients. Acta Otolaryngol 114: 572-575, 1994

11) Geddes JF, Bhattacharjee MB, Savage K, Scaravilli F, McLaughlin JE: Primary cerebral lymphoma: a study of 47 cases probed for Epstein-Barr virus genome. J Clin Pathol 45: 587-590, 1992

12) Gulley ML: Molecular diagnosis of Epstein-Barr virus-related diseases. J Mol Diagn 3: 1-10, 2001

13) Hamilton-Dutoit SJ, Raphael M, Audouin J, Diebold J, Lisse I, Pedersen C, Oksenhendler E, Marelle L, Pallesen G: In situ demonstration of Epstein-Barr virus small RNAs (EBER 1) in acquired immunodeficiency syndrome-related lymphomas: correlation with tumor morphology and primary site. Blood 82: 619-624, 1993

14) Hanel M, Fiedler F, Thorns C: Anti-CD20 monoclonal antibody (Rituximab) and Cidofovir as successful treatment of an EBV-associated lymphoma with CNS involvement. Onkologie 24: 491-494, 2001

15) Harada S, Kamata $Y$, Ishii $Y$, Eda H, Kitamura R, Obayashi M, Ito S, Ban F, Kuranari J, Nakajima H, Kuze T, Hayashi M, Okabe N, Senpuku H, Miyasaka N, Nakamura Y, Kanegane H, Yanagi K: Maintenance of serum immunoglobulin $\mathrm{G}$ antibodies to Epstein-Barr virus (EBV) nuclear antigen 2 in healthy individuals from different age groups in a Japanese population with a high childhood incidence of asymptomatic primary EBV infection. Clin Diagn Lab Immunol 11: 123-130, 2004

16) Hirose Y, Masaki Y, Sasaki K, Ogawa Y, Takeshita S, Fukutoku M, Sugai S, Takiguchi T: Determination of Epstein-Barr virus association with B-cell lymphomas in Japan: study of 72 cases - in situ hybridization, polymerase chain reaction, immunohistochemical studies. Int J Hematol 67: 165-174, 1998

17) Itoyama $\mathrm{T}$, Sadamori $\mathrm{N}$, Tsutsumi K, Tokunaga $\mathrm{Y}$, Soda H, Tomonaga M, Yamamori S, Masuda Y, Oshima K, Kikuchi M: Primary central nervous system lymphomas. Immunophenotypic, virologic, and cytogenetic findings of three patients without immune defects. Cancer 73: 455-463, 1994

18) Khan G, Miyashita EM, Yang B, Babcock GJ, Thorley-Lawson DA: Is EBV persistence in vivo a model for B cell homeostasis? Immunity 5: 173-179, 1996

19) Kleihues P, Cavenee WK: Pathology and Genetics of Tumors of the Nervous System. Lyon, International Agency for Research on Cancer, World Health Organization, 1997, pp 154-159

20) Knowles DM: Molecular pathology of acquired immunodeficiency syndrome-related non-Hodgkin's lymphoma. Semin Diagn Pathol 14: 67-82, 1997

21) Krogh-Jensen M, Johansen P, D'Amore F: Primary central nervous system lymphomas in immunocompetent individuals: histology, Epstein-Barr virus genome, Ki-67 proliferation index, p53 and bcl-2 gene expression. Leuk Lymphoma 30: 131-142, 1998

22) MacMahon EM, Glass JD, Hayward SD, Mann RB, Becker PS, Charache P, McArthur JC, Ambinder RF: Epstein-Barr virus in AIDS related primary central nervous system lymphoma. Lancet 338: 969-973, 1991

23) Mizoroki F, Hirose $Y$, Sano M, Fukuda H, Tobinai K, Nakata M, Taniwaki M, Kawano F, Uozumi K, Sawada K, Fukuhara S, Nasu K, Ohno Y, Toki H, Togawa A, Kikuchi M, Hotta T, Shimoyama M; Japan Clinical Oncology Group-Lymphoma Study Group (JCOGLSG): A phase II study of VEPA/FEPP chemotherapy for aggressive lymphoma in elderly patients: Japan Clinical Oncology Group Study JCOG9203. Int J Hematol 83: 55-62, 2006

24) Murphy JK, Young LS, Bevan IS, Lewis FA, Dockey D, Ironside JW, O’Brien CJ, Wells M: Demonstration of Epstein-Barr virus in primary brain lymphoma by in situ DNA hybridisation in paraffin wax embedded tissue. J Clin Pathol 43: 220-223, 1990

25) Panageas KS, Elkin EB, DeAngelis LM, Ben-Porat L, Abrey LE: Trends in survival from primary central nervous system lymphoma, 1975-1999: a populationbased analysis. Cancer 104: 2466-2472, 2005

26) Rao CR, Jain K, Bhatia K, Laksmaiah KC, Shankar SK: Association of primary central nervous system lymphomas with the Epstein-Barr virus. Neurol India 51: 237-240, 2003

27) Rossi D, Gaidano G: Molecular heterogeneity of diffuse large B-cell lymphoma: implications for disease management and prognosis. Hematology 7: 239-252, 2002

28) Shibata D, Weiss LM: Epstein-Barr-virus-associated gastric adenocarcinoma. Am J Pathol 140: 769-774, 1992

29) Shimoyama Y, Oyama T, Asano N, Oshiro A, Suzuki R, Kagami Y, Morishima Y, Nakamura S: Senile Epstein-Barr virus-associated B-cell lymphoproliferative disorders: a mini review. J Clin Exp Hematop 46: 1-4, 2006

30) Sparano JA: Clinical aspects and management of AIDS-related lymphoma. Eur J Cancer 37: 1296-1305, 2001

31) Tsai CC, Chen CL, Hsu HC: Expression of EpsteinBarr virus in carcinomas of major salivary glands: a strong association with lymphoepithelioma-like carcinoma. Hum Pathol 27: 258-262, 1996

32) Volpi A: Epstein-Barr virus and human herpesvirus type 8 infections of the central nervous system. Herpes 11 Suppl 2: 120A-127A, 2004

33) zur Hausen H, Schulte-Holthausen H, Klein G, Henle W, Henle G, Clifford P, Santesson L: EBV DNA in biopsies of Burkitt tumors and anaplastic carcinomas of the nasopharynx. Nature 228: 1056-1058, 1970

Address reprint requests to: Ryuhei Kitai, M.D., Department of Neurosurgery, Faculty of Medical Sciences, University of Fukui, 23-3 Matsuoka Shimoaizuki, Eiheiji-cho, Yoshida-gun, Fukui 910-1193, Japan. e-mail: kitai@u-fukui.ac.jp 